\title{
EL CONCEPTO DE SEGURIDAD SOCIAL: UNA APROXIMACIÓN A SUS ALCANCES Y LÍMITES
}

\author{
Alejandro Pérez y Soto Domínguez* \\ Doctorado en (C) en Economía, Universidad Rey Juan Carlos (España). Máster Oficial en Economía de la Escuela \\ Austriaca (España). Docente Investigador de la Universidad San Buenaventura-Cali (Colombia). \\ Economista. Universidad del Valle (Colombia). \\ Correo electrónico: aperez2@usb.edu.co \\ Yenny Andrea Calderón Ossa \\ Facultad de Ciencias Jurídicas. Universidad Central del Valle, Cauca - Tulua (Colombia). Joven Investigadora \\ Correo electrónico: yacolinda2003@hotmail.com
}

\begin{abstract}
Resumen
Este artículo pretende brindar al lector un acercamiento al origen y desenvolvimiento del concepto de Seguridad Social, tanto en el plano de la tradición occidental, como en el contexto colombiano. Contrario a lo que se ha propuesto por la tradición de la teoría política, proveniente de las nociones de Estado de Bienestar bismakiano, este concepto no procede en estricto, de los órdenes estatales propios del capitalismo moderno, sino que se ha dado en numerosas culturas que datan desde la época precolombina, hasta nuestros días. En definitiva, se trata de un ejercicio en el que el hombre procura protegerse frente a la incertidumbre y donde la cooperación social aparece como alternativa para esta protección, no obstante, este concepto ha sido cooptado por el Estado Moderno involucrándolo como una de sus funciones sustantivas.
\end{abstract}

Palabras Clave: Seguridad Social, Estado de Bienestar, Estado Moderno, cooperación social.

\begin{abstract}
This article aims to provide an approach to the origin and development of the concept of social security at both the Western tradition, as in the Colombian context. Contrary to what has been proposed by the tradition of political theory, from the notions of Bismak's welfare state, this concept does not apply instrict orders of the state characteristic of modern capitalism, but has occurred inmany cultures dating from pre-Columbian times to today. In short, it is an exercise in which men seek to hedge against the uncertainty and where social cooperation appears as an alternative to this protection, however, this concept has been adopted by the modern state involving them as one of its substantive functions.
\end{abstract}

Key Words: NationalHealthService, Welfarestate, Modern State, social cooperation.

\section{Résumé}

Cetarticleessaied'offriraulecteur un rapprochement à l'origine et le déroulement du concept de Sécuritésociale, dans le plan de la traditionoccidentale, et dans le contextecolombien. Je contrarie à ce qu'ils'estproposépar la tradition de la théoriepolitique, provenante des notionsd'État-providencebismakiano, ce concept neprocèdepasdansstrict, des ordresétatiquespropres du capitalismemoderne, maisils'estrendudans les nombreuses cultures quidatentdepuisl'époqueprécolombienne, jusqu'à nos jours. En définitive, ils'agitd'unexercice de celui que l'hommeessaie de se protéger en face de l'incertitude et où la coopérationsocialeapparaîtcommealternativepourcetteprotection, cependant, ce concept a été coopté par l'ÉtatModerne en l'impliquantcommel'une de sesfonctions substantives

Mots-clés: Une sécuritésociale, un État-providence, un ÉtatModerne, une coopérationsociale. 

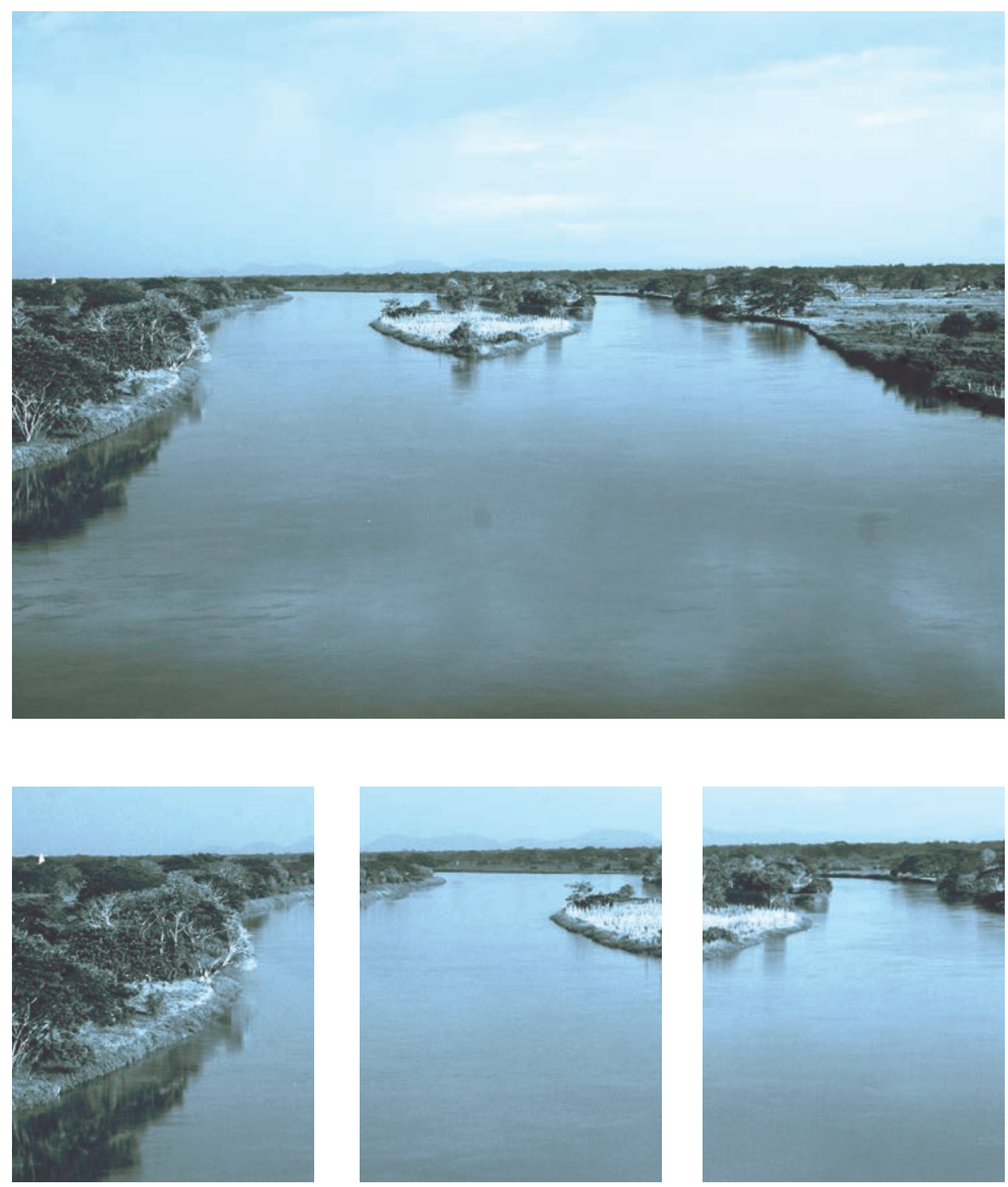

Rio Magdalena - Mompóx - Colombia

Martín Emilio Hernández Manrique 


\section{EL CONCEPTO DE SEGURIDAD SOCIAL: UNA APROXIMACIÓN A SUS ALCANCES Y LÍMITES}

Alejandro Pérez y Soto Domínguez

Yenny Andrea Calderón Ossa

\footnotetext{
"El sistema de gobierno más perfecto, es aquel que produce mayor suma de felicidad posible, mayor suma de seguridad social y mayor suma de estabilidad política"

Simón Bolívar (Discurso de Angostura, 15 de Febrero de 1819)
}

\section{INTRODUCCIÓN}

La Seguridad Social es un concepto de difícil tratamiento, ya que toca las áreas de la Economía y la Ciencia Política de manera especial. Se asume como un concepto de esencia plenamente económica, en tanto se refiere, a la gestión de unos recursos de naturaleza escasa y que requieren ser administrados bajo los principios de eficiencia, eficacia y celeridad. Al mismo tiempo, es un concepto que asume un rol eminentemente político, toda vez, que se asume como una característica sustantiva del ejercicio político del Estado Moderno. Aunque esta visión de asumir al Estado como un instrumento de redistribución igualitaria de los recursos producto del trabajo, ha sido bandera tradicional de los países de la extinta cortina de hierro, y aunque el comunismo internacional ha desaparecido hoy, su espíritu redistributivo, también fue asumido como bandera fundamental de los partidos social-demócratas y su difusión como un aspecto propio del Estado, llegó también a ser aceptado por los

\footnotetext{
* El presente texto se deriva del proyecto de investigación: El orden mercantil: sus elementos epistemológicos e institucionales. Grupo de Investigación Economía, Gestión, Territorio y Desarrollo Sostenible (GEOS). Facultad de Ciencias Económicas. Universidad San Buenaventura, Cali (Colombia).
} 
partidos de centro derecha, en especial, en los casos de España, Francia, Alemania e Italia, así como en numerosos países de la Unión Europea.

En la actualidad, la crisis económica mundial ha obligado revaluar la viabilidad fiscal de la seguridad social como una política de Estado. Sin lugar a dudas, el concepto de seguridad social tendrá que ser revisado con sumo cuidado, del mismo modo, se tendrá que reevaluar como su provisión en cabeza del Estado, así como su modelo "mixto" o mercantilista, que asume el principio de privatización de ganancias con socialización de pérdidas, tal vez sea tiempo de repensar la provisión desde las perspectiva de un escenario libre de competencia abierta. Curiosamente la vía del libre mercado y de la provisión espontánea de servicios sociales es la única que no se ha llevado a una práctica efectiva, lo cual llama bastante la atención, en especial, cuando la tradición occidental proveniente de la Carta Magna (1215) y de la Revolución gloriosa (1688), siempre ha defendido desde el discurso el libre mercado y la libertad de empresa, aunque en la práctica su ejercicio transite del socialismo al mercantilismo y de regreso.

Desde la teoría económica tradicional se ha argumentado la imposibilidad del mercado de proveer este tipo de bienes ${ }^{1}$, los cuales se enmarcan dentro de las fallas de mercado, se dice que privadamente no se produciría la cantidad de bienes que la sociedad demandaría, en razón de esto, se hace importante la intervención del Estado, que ha ido desde asumir directamente la provisión de dichos servicios hasta formular reglas para que los particulares los presten, uno y otro han mostrado falencias por lo cual es importante reflexionar sobre una tercera vía. ¿Por qué no tomar la opción del mercado y su orden espontáneo? Varios ejemplos en la historia dan cuenta de organizaciones de provisión de tales servicios a cargo de la iniciativa privada.

La Seguridad Social en nuestro país, también es un concepto de abordaje complejo, ya que muchos de sus conceptos son elaboraciones que se han importado y se han impostado en el esquema nacional, sin atender a las dinámicas propias de nuestras deficiencias institucionales, tales como la dificultad de implantación de los derechos de propiedad, la ausencia de legitimidad por parte del Estado, la incapacidad para el ejercicio del monopolio en el uso de la fuerza, así como la provisión de servicios sociales, que desde su implantación en el país ha atendido a una lógica clientelar que no procura una provisión efectiva y eficiente de los servicios, sino que se asume como una pieza más del esquema político electoral, dado el peso que tienen estos servicios en las cuentas públicas y los ingresos potenciales que estos pueden representar para las entidades territoriales.

El concepto de seguridad social en el caso colombiano, desde el manejo

Que incluyen bienes tan diferentes y variados como los referidos a la atención en salud, la asistencia a desamparados o a personas con una situación de debilidad manifiesta o especial protección; pobreza, vejez, discapacidades, etc. Sólo lo denominado salud incluye: atención en salud (servicios), saneamiento básico, promoción y prevención de enfermedades, lo cual puede formar una masa enorme de intervenciones a cargo del Estado que ocuparían todos los aspectos del desarrollo humano, tal como ha pasado en los últimos dos siglos. 
legislativo, y en especial, a partir de la entrada en vigencia de la Constitución de 1991, ha sido asumido como un elemento ligado a instituciones sociales, políticas y económicas existentes que ante los cambios constitucionales deben adecuar a las implicaciones de garantizar la concepción de dignidad humana ${ }^{2}$ tratado en la Carta Magna. Hoy su provisión, se ha diseñado en cabeza del Estado bajo, una estructura mercantilista, que se acoge en la figura de servicio público social con el concurso de los particulares, por esto lo encontramos consignado en el artículo 48 de nuestra Constitución Política ${ }^{3}$; también se puede concordar con los artículos 44 y $46^{4}$,que se refieren a los derechos de los niños, y adolescentes, donde también se establece que es un servicio fundamental y una obligación estatal.

Regularmente se utiliza este término para referirse al régimen de salud y pensión, pero como se dijo anteriormente va más allá, por cuanto involucra derechos fundamentales de los ciudadanos comunes, así como de comunidades vulnerables tales como los de los niños, personas en discapacidad o de la tercera edad que no pueden valerse por sí mismos, para quienes el Estado tiene la obligación de proveer dicha seguridad y bienestar. De allí la importancia de este trabajo: conocer qué es la Seguridad Social al interior del marco constitucional y normativo, cómo ha sido su evolución histórica a nivel nacional y global, quién es el responsable de proveer dichos servicios y a quién va dirigido y conocer más de cerca su aplicación; así mismo, poder establecer su importancia para el bienestar de todos los ciudadanos.

\section{CONCEPTO LEGAL DE SEGURIDAD SOCIAL}

En esta sección, se desea presentar una serie de definiciones acerca del concepto legal de seguridad social. Esta presentación se elabora con el objetivo de llamar la atención sobre el sentido político que tienen en común: la intervención del Estado sobre la economía. Cuando el Estado Moderno se erige como gran gestor del bienestar humano, emergen conceptos tales como dignidad humana, derechos humanos, y otros conceptos ligados con lo humano, que se refiere al acceso incondicional de ciertos bienes y servicios. No obstante, esta provisión lleva consigo dos elementos claros, por una parte, se afianza el sentido de un contrato de vasallaje en el que el ciudadano abdica su capacidad de gobernarse a sí mismo, y más aún, entrega la posibilidad de

2 La dignidad, o "cualidad de digno", deriva del adjetivo latino dignus y se traduce por "valioso". Hace referencia al valor inherente al ser humano, dotado de libertad, raciocinio e inteligencia, con capacidad para modelar y mejorar sus vidas mediante la toma de decisiones y el ejercicio de su libertad. Se tiende a afirmar que el ser humano posee dignidad por sí mismo, es decir, se tiene desde el mismo instante de su fecundación o concepción; es inalienable e inviolable. No es un derecho propiamente dicho, pero constituye el fundamento de los derechos que se le conceden al hombre; por ello los Tratados Internacionales y las Constituciones del mundo la reconocen como el fin último de la existencia humana.

3 Constitución Política de Colombia. (1991). Artículo 48

4 Ibidem. Artículos 44 y 46. 
gestionar los recursos de su trabajo, a cambio que la institucionalidad del Estado asuma la responsabilidad de administrar por él tales recursos, y le garantice la provisión de este mínimo vital.

Se constituye a todas luces, como un proceso de sustitución de la elección individual, por una elección colectivista, que en cabeza de un ingeniero social, puede decidir qué es lo que más conviene a cada una de los personas bajo su gobierno. Se trata de un esquema en que el ciudadano es reducido a la condición Kantiana de minoría de edad ${ }^{5}$, en la que el Estado, dada la incapacidad del individuo, asume la tarea de salvarle de las malas decisiones y de proveerle en cambio una canasta de bienes y servicios adecuada con lo que se ha definido como dignidad humana.

La Seguridad Social Integral en Colombia, es una institución legal, reglamentada especialmente para proteger los llamados derechos fundamentales, entre los que se encuentran: la vida, salud e integridad de todos los ciudadanos. Se llama Seguridad Social debido a que desde el plano normativo, tiene la pretensión de brindar seguridad a toda la población, desde la provisión de estos llamados "servicios elementales" sin distinciones basadas en raza, edad, sexo o condición socioeconómica; y es integral porque abarca un grupo de protecciones especiales para los trabajadores y sus familias; igualmente quienes se encuentren en condición de vulnerabilidad ${ }^{6}$, también pueden beneficiarse de la seguridad social pues es un servicio público de obligatorio cumplimiento a cargo del Estado.

En una palabra el sistema de seguridad social sirve a dos propósitos fundamentales: legitimidad y financiación. En cuanto a legitimidad, la provisión de servicios sociales a escala ampliada a la población, tiende a reivindicar el papel del Estado como garante de la protección de todos los individuos, protección no solamente frente a los derechos de propiedad individual o frente a la agresión física, sino también protección frente al acceso de servicios elementales que son separados de la lógica de la asignación espontanea del mercado, para encontrarse sujetos a la lógica clientelar propia de la provisión de beneficios de los gobernantes sobre el electorado.

Estas protecciones hacen parte de unos regímenes especiales como son las pensiones, los riesgos profesionales, la salud y servicios complementarios. Algunas definiciones al respecto las muestran autores como José Pérez Leñero al afirmar que es "parte de la Ciencia Política la cual, mediante instituciones técnicas de ayuda, previsión o asistencia, defiende o propulsa la paz y la prosperidad general de toda la población a través del bienestar individual de sus miembros"'. Rubén Greco dice que: "La Seguridad Social es una realidad política, jurídica, técnica y práctica, que

6 Una situación de vulnerabilidad se define como "una condición social de riesgo, de dificultad, que inhabilita e invalida, de manera inmediata o en el futuro, a los grupos afectados, en la satisfacción de su bienestar, en tanto subsistencia y calidad de vida, en contextos socio históricos y culturalmente determinados". Perona, Nélida, (2000). Vulnerabilidad y Exclusión social. Una propuesta metodológica para el estudio de las condiciones de la vida de los hogares. Revista Kairos. Universidad Nacional de San Luis. Argentina.

7 Pérez Leñero, J. (1956), Fundamentos de la Seguridad Social, (p. 35). Madrid. 
tiene por objeto la cobertura de determinadas contingencias consideradas como protegibles, mediante organismos estatales o privados, financiados con recursos propios". ${ }^{8}$

Otras acepciones modernas, consideran la Seguridad Social, como sinónimo de Bienestar Social ${ }^{9}$, enmarcado en un bloque constitucional y normativo; José Bernedo Alvarado la define como "un derecho fundamental y al mismo tiempo como un instrumento de justicia social"10. El cual "Para cumplir con estas finalidades, debe basarse en los principios fundamentales de universalidad, solidaridad, igualdad, suficiencia, participación y transparencia"'ll. En su concepción moderna, la Seguridad Social es considerada un componente insoslayable del sistema de protección social integral de la persona humana que implica el “(...) asegurar los ingresos indispensables para que las personas puedan vivir con dignidad y decoro; esta condición es, al mismo tiempo, un pilar esencial de los derechos humanos primordiales ${ }^{\prime 2}$. Desde esta perspectiva, tanto los aspectos institucionales como administrativos, de la Seguridad Social deben estar al servicio del fin superior que

$8 \quad$ Greco R. (1968), Revista de Seguridad Social, No. 6, 518. Buenos Aires.

9 Se llama Bienestar Social al conjunto de factores que participan en la calidad de vida de las personas y que hacen que su existencia posea todos aquellos elementos que dé lugar a la tranquilidad y satisfacción humana.

10 La Justicia Social es un concepto aparecido a mediados del siglo XIX, referido a las situaciones de desigualdad social, que define la búsqueda de equilibrio entre partes desiguales, por medio de la creación de protecciones a favor de los más débiles. Remite al derecho de los sectores más desfavorecidos de la sociedad, en especial los trabajadores, y al goce de los derechos humanos sociales y económicos, de los que ningún ser humano debería ser privado. La idea de justicia social está orientada a la creación de las condiciones necesarias para que se desarrolle una sociedad relativamente igualitaria en términos económicos. Comprende el conjunto de decisiones, normas y principios considerados razonables para garantizar condiciones de trabajo y de vida digna para toda la población. Involucra también la concepción de un Estado activo, removiendo los obstáculos que impiden el desarrollo de relaciones en igualdad de condiciones.

11 Bernedo Alvarado, J. (2000), Informe regional sobre la situación de la Seguridad Social como un Derecho Humano en América Latina, Párrafo 1. Lima (Perú).

12 El derecho fundamental al mínimo vital ha sido reconocido desde 1992 en forma extendida y reiterada por la jurisprudencia constitucional de la Corte como un derecho que se deriva de los principios de Estado Social de derecho, dignidad humana y solidaridad, en concordancia con los derechos fundamentales a la vida, a la integridad personal y a la igualdad en la modalidad de protección especial a personas en situación de necesidad manifiesta. El objeto del derecho fundamental al mínimo vital abarca todas las medidas constitucionalmente ordenadas con el fin de evitar que la persona se vea reducida en su valor intrínseco como ser humano debido a que no cuenta con las condiciones materiales que le permitan llevar una existencia digna. Este derecho fundamental busca garantizar que la persona, centro del ordenamiento jurídico, no se convierta en instrumento de otros fines, objetivos, propósitos, bienes o intereses, por importantes o valiosos que ellos sean. Tal derecho protege a la persona, en consecuencia, contra toda forma de degradación que comprometa no sólo su subsistencia física sino, por sobre todo, su valor intrínseco. Por ello, la jurisprudencia bajo el derecho fundamental al mínimo vital ha ordenado al Estado, entre otras, reconocer prestaciones positivas a favor de personas inimputables, detenidas, indigentes, enfermos no cubiertos por el sistema de salud y mujeres embarazadas, entre otras. 
constituye el bienestar general de la población.

La Oficina Internacional del Trabajo (OIT), en la Conferencia Internacional del Trabajo, LXXXIX reunión, 2001, en su segundo apartado sobre las conclusiones relativas a la Seguridad Social destaca la importancia de esta como un elemento fundamental de las políticas de los Estados de la siguiente manera: "La Seguridad Social es muy importante para el bienestar de los trabajadores, de sus familias y de toda la sociedad. Es un derecho humano fundamental ${ }^{13}$, y un instrumento esencial para crear cohesión social ${ }^{14}$, y de ese modo contribuye a garantizar la paz y la integración social. Forma parte indispensable de la política social de los gobiernos $y$ es una herramienta importante para evitar y aliviar la pobreza. A través de la solidaridad nacional y la distribución justa de la carga, puede contribuir a la dignidad humana, a la equidad y a la justicia social. También es importante para la integración política, la participación de los ciudadanos y el desarrollo de la democracia". ${ }^{15}$

Guillermo Cabanellas de Torres comenta que la

"Seguridad Social integra el conjunto de normas preventivas y de auxilio que todo individuo por el hecho de vivir en sociedad recibe del Estado, para hacer frente asi a determinadas contingencias previsibles y que anulan su capacidad de ganancia. Para otro análisis se está ante los medios económicos, que se le procuran al individuo, con protección especial, para garantizarle un nivel de vida suficiente, de acuerdo con las condiciones generales del país y en relación con un momento dado". ${ }^{16}$

El tratadista Julio Armando Grisolia dice que:

"El derecho de la Seguridad Social es el conjunto de normas jurídicas que regulan la protección de las denominadas contingencias sociales ${ }^{17}$, como la salud, la vejez o la desocupación. Se trata de casos de necesidad biológica y

13 En Colombia, la Seguridad Social no es un derecho fundamental sino una obligación estatal, aunque para muchos tratadistas debería elevarse a esta categoría por las implicaciones sociales, políticas y económicas que tiene para todos los ciudadanos, especialmente los que se encuentran en situación de vulnerabilidad. Es necesario pues que se consolide la seguridad social como un derecho fundamental, por considerarse un sistema de protección social universal, indispensable en la organización social de todos los países.

14 De esta forma disminuir las diferencias sociales, lo que significaría un nuevo giro a las políticas nacionales e internacionales al encontrar una aplicación correcta de los derechos fundamentales como el de la igualdad, pues la brecha que separa los estratos sociales se haría más angosta: más empleo, menos pobreza y demás.

15 Oficina Internacional del Trabajo, (2001), Seguridad Social Un nuevo consenso, (p. 1 - 2). Ginebra (Suiza).

16 Cabanellas de Torres, G., (2001). Diccionario de Derecho Laboral. Ed. 1. Heliasta. Buenos Aires. p. 558.

17 Las Contingencias Sociales se clasifican según la obra del maestro español Severino Aznar (1947) de la siguiente manera: de origen patológico: la enfermedad, la invalidez y el accidente de trabajo. De origen principalmente biológico: la maternidad, la vejez y la muerte. De origen económico social: el paro forzoso y las excesivas cargas familiares. Esta clasificación aún tiene plena vigencia y es acogida doctrinaria y jurisprudencialmente en la mayoría de países del mundo. 
económica. Es una rama del derecho que ampara al trabajador dependiente, al autónomo y también al desempleado, de las contingencias de la vida que pueden disminuir la capacidad de ganancia del individuo. Se materializa mediante un conjunto de medidas y garantías adoptadas a favor de los hombres para protegerlos contra ciertos riesgos"'18.

Los tratadistas citados concuerdan en que la Seguridad Social corresponde a políticas gubernamentales indispensables para la vida de las personas en procura de la realización efectiva de la dignidad humana, que se compone de tres elementos esenciales que son: salud, pensión y riesgos profesionales con lo que se pretende hacerla integral ${ }^{19}$. Pero, sin duda alguna, la definición más clara y completa sobre la Seguridad Social Integral con todas sus implicaciones y principios nos la trae la Ley 100 decretada el 23 de Diciembre de 1993, en la cual se crea "el Sistema de Seguridad Social Integral en Colombia" y que la define de la siguiente manera:

"La Seguridad Social Integral es el conjunto de instituciones, normas y procedimientos, de que disponen la persona y la comunidad para mejorar la calidad de vida, mediante el cumplimiento progresivo de los planes y programas que el Estado y la sociedad desarrollen para proporcionar la cobertura integral de las contingencias, especialmente las que menoscaban la salud y la capacidad económica de los habitantes del territorio nacional, con el fin de lograr el bienestar individual y la integración de la comunidad". ${ }^{20}$

En esta definición los juristas integraron el bloque Constitucional y legal con las políticas estatales, para promulgar una ley que orientara la administración y funcionamiento del bienestar a cargo del Estado en la Seguridad Social Integral. La cual superó conceptual y prácticamente a la previsión social ${ }^{21}$ y a la asistencia pública $^{22}$ y se autonomizó del derecho laboral hace varias décadas. Se define como

18 Grisolia, J. (2003), Derecho del Trabajo y de la Seguridad Social, (p. 923). Buenos Aires: Ediciones Desalma Lexis Nexos.

19 Para algunos tratadistas responde a políticas de salud pública, de orden público o de contenido económico, para otros es un conjunto de estos; lo cierto es que con la vinculación de la Seguridad Social a las legislaciones del mundo se pretende constituirla como un derecho fundamental inalienable e inviolable a cargo del Estado.

20 Plazas, G. (1994), La nueva Seguridad Social, texto comentado de la Ley 100 de 1993, (p. 21). Colombia.

21 Entiéndase Previsión Social como un sistema de seguro que el Estado impone obligatoriamente a todos los trabajadores con la finalidad de protegerlos, también a sus dependientes, contra eventualidades como la pérdida de sus condiciones de trabajo por accidentes, enfermedades, vejez o muerte.

22 Asistencia Pública, es un sistema de ayuda facilitada a aquellos grupos de población que están cerca o por debajo del nivel normal de subsistencia. 
un proceso gradual en el cual participan el Estado y la sociedad ${ }^{23}$. Se encuentra en los Artículos 48 y 49 de la Constitución Política, que definen claramente la Seguridad Social como un servicio público ${ }^{24}$ de carácter obligatorio a cargo del Estado, en sujeción a la ley; textualmente citan:

"La Seguridad Social es un servicio público de carácter obligatorio que se prestará bajo la dirección, coordinación y control del Estado, en sujeción a los principios de eficiencia, universalidad y solidaridad, en los términos que establezca la Ley (...)"25. "La atención de la salud y el saneamiento ambiental son servicios públicos a cargo del Estado. Se garantiza a todas las personas el acceso a los servicios de promoción, protección y recuperación de la salud (...)”26.

De este modo, la Constitución y la normatividad vigente orientan las políticas estatales en procura de la realización efectiva de la seguridad social y protección de las personas. Los artículos 48 y 49 de la Constitución Política, concuerdan con el artículo 44 (ibídem)" que cita los derechos fundamentales de los niños "Son derechos fundamentales de los niños: (...) y la seguridad social (...)” y con el artículo 46 (ibídem), sobre los derechos de las personas de la tercera edad y en estado de indefensión "El Estado, la sociedad y la familia concurrirán para la protección y la asistencia de las personas de la tercera edad (...). El Estado les garantizará los servicios de la Seguridad Social Integral (...)”28.

Queda claro, que el Sistema de Seguridad Social Integral (en adelante SSSI) busca proveer de seguridad económica, salud y bienestar a todas las personas y se encuentra a cargo del Estado, el cual tiene entre otras obligaciones: desarrollar políticas públicas para su desarrollo efectivo, administrarlo y asegurar que los ciudadanos accedan al sistema de Seguridad Social Integral en todo el territorio nacional.

De allí parte su objeto que es el de

23 Se desarrolla por mandato de la Constitución de 1991, y por primera vez en la historia de vida constitucional de nuestro país se le da tal trascendencia.

24 Diversas discusiones se han suscitado sobre este punto, ya que en Colombia la Seguridad Social no es un derecho fundamental pues esta categoría se le ha dado a los derechos naturales como la vida, libertad, igualdad, etc. Sin embargo, diferentes posturas doctrinarias le dan este tratamiento. La Constitución Política de 1991 la define como un Servicio Público a cargo del Estado y es él quien tiene la potestad de autorizar su prestación a entidades privadas como sucede en la actualidad. Se ha dado el significado de servicio público, como un servicio que se debe prestar a todas las personas sin distingo alguno, pero que es susceptible de explotación económica. De allí que muchos juristas y tratadistas del tema sugieran elevar la Seguridad Social a derecho fundamental, para que el Estado procure su realización efectiva.

25 Constitución Política de Colombia (1991), Artículo 48

26 Ibídem, Artículo 49

27 Ibídem, Artículo 44

28 Ibídem, Artículo 46. 
"garantizar los derechos irrenunciables ${ }^{29}$ de la persona y la comunidad para obtener la calidad de vida acorde con la dignidad humana, mediante la protección de las contingencias que la afecten. El sistema comprende las obligaciones del Estado y la sociedad, las instituciones y los recursos destinados a garantizar la cobertura de las prestaciones de carácter económico, de salud y servicios complementarios (...)" ${ }^{\prime 30}$,

y se encuentra orientado por unos principios básicos que sirven de soporte para que el SSSI pueda cumplir con su propósito. Dichos principios son: eficiencia, universalidad, solidaridad, integralidad, unidad y participación.

La ley de Seguridad Social "Ley 100 de 1993", da una definición del SSSI, en la cual toma la Seguridad Social como un derecho frente a unas limitantes condiciones sociales caracterizadas por el incremento de las tasas de desempleo, el alto índice de personas que no se encuentran vinculadas al SSSI, las desigualdades sociales cada vez más notorias. Son indicadores que muestran la falta de políticas públicas claras frente a la seguridad y bienestar de los habitantes; por tanto tal definición como derecho se ajustaría al caso colombiano siempre que el Estado posea los medios para garantizarlo a todos los ciudadanos.

La historia colombiana de los dos últimos siglos indica que la Seguridad Social no ha seguido una forma homogénea de prestación por parte del Estado, por el contrario, da cuenta de esquemas difusos y fracturados, tal como señala Flórez (2011) en las que se pueden identificar tres tendencias, la primera data del periodo finales del siglo XIX a mediados de siglo XX (1880-1936), en la cual coexistieron la forma privada para aquellos con capacidad de pago, formas caritativas a cargo de la iglesia y particulares (por ejemplo la Fundación Rockefeller), para aquellos sin capacidad de pago, así como la brindada por el sincretismo cultural y prácticas no científicas en el caso de la atención en salud por curanderos y chamanes. La segunda fijada por el Estado en la prestación por medio del primer sistema de seguridad social estatal para los empleados públicos (años cuarenta siglo XX), originario de la idea de Bismark, y más adelante, con la implementación de un sistema de salud de provisión estatal directa, Sistema Nacional de Salud mediante el Decreto extraordinario 056 del 15 de enero de 1975. Una tercera fase ${ }^{31}$ se enmarca en el fomento de un sistema de cobertura universal incorporando la provisión privada bajo reglas por medio de la Ley 100 de 1993, a pesar de las reformas de esta Ley, tales como las reflejadas en la Ley 1122 de 2007 y en la Ley 1438 de enero de 2011 no se han ocasionado cambios

29 Tomado de la Ley de Seguridad Social q afirma el SSSI como un derecho pero como se explicó es un servicio público a cargo del Estado.

30 Ministerio de la Protección Social, Instituto de los Seguros Sociales. Ley de Seguridad Social (Ley 100 de 1993).

31 Flórez, K (2011). La competencia Regulada en el sistema de salud colombiano. Revista Lebret, 2 48-73. 
sustanciales, la primera enfatiza en la papel regulador y la segunda de nuevas formas de financiación del sistema (impuestos) ${ }^{32}$.

En resumen, puede destacarse que existe un consenso ampliamente difundido en el ambiente académico, acerca de una ligazón indisoluble entre bienestar y Estado, entre Estado de bienestar y protección social. En todo caso, se trata de que el Estado asuma una función plenamente económica y abandone su papel de espectador y árbitro frente al juego económico, erigiéndose como juez y parte en la convivencia de intereses propias de las sociedades civiles.

\section{EVOLUCIÓN HISTÓRICA}

En esta sección se desea presentar un acercamiento al desenvolvimiento histórico del concepto de seguridad social y su aplicación en las diferentes formas de organización social, que el ser humano ha experimentado en las diferentes combinaciones de espacio y tiempo. Este ejercicio se propone con el objeto de revertir la noción ampliamente extendida, que la gestión frente a las situaciones de riesgo e incertidumbre únicamente puede ser gestionada por la institucionalidad del Estado. Lejos de esta concepción, la noma general hasta poco antes del siglo XX, era que los colectivos humanos generaban redes de asistencia y protección mutuas, en las que sin la necesidad de un Estado de Bienestar, si se daba la gestión de una Sociedad del Bienestar.

Durante siglos, el hombre ha visto en la organización social un espacio de protección frente a las fuerzas de la naturaleza y una ventaja técnica derivada de la división del trabajo. Dadas las inclemencias del clima y las fuerzas naturales, como la incertidumbre frente a la recolección, la caza y la pesca, o frente a los resultados del ejercicio de la agricultura, así como a fenómenos de tipo catastrófico. Los múltiples experimentos de desenvolvimiento espontáneo, por medio del proceso de ensayo y error han conducido al hombre a buscar mecanismos de previsión frente a aquello que se encuentra por fuera de su alcance y a darle una gestión a las deficiencias materiales derivadas de aquellos eventos inesperados.

De este modo, la formación de núcleos familiares, trae consigo, la necesidad de asociarse para mejorar las condiciones de vida propia y de quienes dependían de él ${ }^{33}$, ya no piensa en su propia protección y bienestar sino en la de un grupo que esperan que él se convierta en su benefactor; aquí nacen las primeras formas de sociedad Las Tribus. Mallet lo describe así:

"El ansia de seguridad ha sido el motor del progreso de la humanidad. La invención de la agricultura fue una forma de asegurarse alimento en vez del aleatorio método de la caza y la recolección de frutos silvestres. La agrupación

32 Por ejemplo en la Ley 1438 de 2011 en el artículo 48 aumenta el monto del impuesto creado por la Ley 100: impuesto Social a las Armas y Municiones de un monto equivalente a $10 \%$ de un salario mínimo mensual al $30 \%$ de un salario mínimo mensual.

33 Sociabilidad natural basada en la interdependencia. 
en tribus, la formación de aldeas, de ciudades, la constitución de Estados, traducen el deseo de seguridad frente a un enemigo exterior". ${ }^{34}$

Estas formas de asociación se basaron en el principio de la solidaridad ${ }^{35}$ orgánica, $^{2}$ propia de las formaciones comunitarias (véase Weber, 1993) ${ }^{36}$, para subsistir como grupo en las condiciones más agrestes. Siglos después las formas de asociación se perfeccionaron de acuerdo a factores de tiempo, modo y lugar, es decir, las condiciones sociales, económicas y culturales variaban según el momento histórico y el lugar donde se vivía.

Las cofradías que surgieron en el mundo en el siglo XIV, al amparo de la iglesia católica, tuvieron como fines la ayuda mutua y religiosa; las hermandades, surgieron en la segunda mitad del siglo XVI y se basaron en el socorro por enfermedad y muerte; entre otras. Fueron asociaciones de mutua ayuda basadas en la solidaridad, las cuales tenían la obligación de atender a los ancianos, minusválidos y socorrer a los enfermos, así mismo, educar los hijos de quienes perecían en defensa de los Estados. Esta ayuda mutua, se debió a la doctrina cristiana sobre el amor al prójimo y la caridad, sobre todo en la Edad Media cuando el oscurantismo religioso torturaba y sacrificaba vidas en nombre de Dios; esta cooperación es considerada como: "El hito fundamental en la histórica evolución de la Seguridad Social ". ${ }^{37}$

De este modo, se formaron las asociaciones y agremiaciones basadas en los principios de solidaridad, seguridad y ayuda mutua que se extendían al de socorrer a los familiares de los muertos con las exequias fúnebres por razones de humanidad y salubridad. En la América prehispánica, también se hizo evidente el deseo de protección y bienestar de los miembros de las tribus; ejemplo de esto, en el imperio Tahuantinsuyo $^{38}$ los incas:

34 Mallet, A., (1983). Estudio de la Seguridad Social: La Búsqueda de la Seguridad Social. Ginebra, p. 78 .

35 La solidaridad, como tercer pilar del Estado Social de Derecho, es un principio fundamental del que se derivan múltiples principios como la equidad, derechos como el de la seguridad social o deberes como a obrar con acciones humanitarias ante situaciones que pongan en peligro la vida o la salud de las personas, todos ellos aplicables tanto al Estado como a los particulares.

36 Weber, M.(1993) Economía y Sociedad. Alianza Editorial. Madrid.

37 Ahumada Pacheco, H., (1972). Manual de Seguridad Social. Chile. Ed. Andrés Bello, p. 16.

38 El Tahuantinsuyo o antiguo imperio inca, existió en la América Prehispánica. Su nombre proviene de la lengua quechua Tawantin Suyu, que significa "Las cuatro divisiones". Fue uno de los imperios más extensos de la humanidad, que abarcaba desde el sur de Colombia, todo el territorio peruano, parte del ecuatoriano, hasta Chile. Se calcula que fueron cerca de 2 millones de $\mathrm{Km}^{2}$, lo que comprendió su territorio. Se constituyó en una de las organizaciones políticas más destacadas de la antigüedad: a la cabeza se encontraba el Inca por derecho divino, asistido por los Apo, que administraban los Suyos, es decir las cuatro grandes regiones divididos, a su vez, en Ayllus, componentes básicos de comunidad ligados por la sangre, la tierra y la divinidad totémica. 
"Garantizaron a la totalidad de los seres humanos bajo su jurisdicción, el derecho a la vida mediante la satisfacción plena de las necesidades físicas primordiales como la alimentación, vestido, vivienda y salud, que equivalía a la supresión del hambre y la miseria causados por las desigualdades sociales y por los no previstos efectos destructores de la naturaleza, incontrolables por el hombre". ${ }^{39}$

En efecto, los sobrantes de los cultivos del Inca eran depositados en piruas o graneros del Estado para cubrir la escasez en épocas de sequía o de calamidad pública; atender a los ancianos, huérfanos y viudas a cargo del Estado y no abandonarlos como ocurría en otras culturas. De la misma forma el sentido comunitario inspirado en la solidaridad permitía que los miembros de un Ayllu ${ }^{40}$, después de cumplir con sus labores comunales, colaboraran con los otros Ayllu que requerían su ayuda.

En estos ejemplos se pone de presente una coincidencia: las organizaciones humanas, sean de orientación comunitaria o societaria ${ }^{41}$ (Tönnies,2009), de manera espontánea han formulado diferentes mecanismos basados en la cooperación social para precaverse frente a las inclemencias del tiempo y sus eventos inesperados, o frente a la simple precariedad material asociada a la enfermedad y vejez, de este modo, el hombre en su afán de protección, seguridad y subsistencia, ha desarrollado las diferentes formas de Seguridad Social acordes al momento histórico y lugar donde vive, en procura de precaverse frente a "los riesgos y contingencias sociales". Empero, la formulación de estos sistemas no ha implicado necesariamente la puesta en marcha de una estructura burocrática o inteligencia directriz que esté tras todo el andamiaje de provisión y distribución en caso de necesidad, sino que a menudo ha sido agenciado por particulares.

Antes de iniciar un recorrido histórico por las épocas moderna y contemporánea, cabe aclarar que la seguridad social tuvo una transición entre una época y otra, se inicia con la época de la instauración por parte del Estado de los seguros sociales y en la medida que las legislaciones cambian al correr del tiempo, el término se va transformando al de seguridad social. Este recorrido inicia con algunos de los hechos más trascendentales en la historia de la humanidad que han influido notoriamente en las transformaciones socioculturales, económicas y políticas de la misma.

Aunque los diferentes autores los teóricos del Estado de Bienestar identifican el inicio de esta política social con las aplicaciones de Bismark en el final del siglo XIX, es menester tomar en consideración que anterior a la implantación en términos efectivos de este sistema de aseguramiento, ya existía una base política que abría la posibilidad para que el Estado interviniese sobre la vida particular de los individuos so pretexto de salvarles frente a la incertidumbre que señalábamos arriba.

39 Valcarcel, L. E. (1964). Historia del Perú antiguo Incas. T. 1. Lima. Ed. Juan Mejía Baca, p.35.

40 Hoy llamadas comunidades campesinas, estaban formadas por personas con vínculos familiares o ficticios de origen totémico, que cultivaban la tierra en común.

41 Tónnies, F (2009). Comunidad y Asociación. Comares. Granada 
El constitucionalismo francés, derivado de la revolución francesa de 1789 se erige como un punto de inflexión y no retorno en el que se otorga al Estado Moderno la función de proteger al hombre frente a la incertidumbre de las fuerzas naturales y a proveerle un mínimo vital, en este proceso, bajo las premisas de libertad, igualdad y fraternidad, se proclamaron los Derechos del Hombre y del Ciudadano (1789), en los cuales se postulan una serie de "conquistas" de la humanidad, las cuales, para ser llevadas a términos efectivos, requieren de una carga fiscal sobre los ciudadanos, con la consiguiente carga impositiva. El constitucionalismo de inspiración en la Francia revolucionaria, así como la Carta de derechos que se derivaron de este proceso se constituyen como la base política en la que descansa la intervención del Estado sobre la economía y en especial, el proceso mediante el cual el Estado captura una parte importante del producto nacional y lo usa discrecionalmente al amparo del llamado "bienestar general". No obstante, aunque ya Francia propone la base política, la base técnica demorará un siglo más en llegar.

En Colombia, se inicia con el desarrollo de políticas asistenciales como el resto de países del mundo; el desarrollo de la independencia trae consigo ideales de libertad, seguridad, trabajo y bienestar para el pueblo, ideales que fueron liderados por los próceres libertadores como Simón Bolívar ${ }^{42}$ y Antonio Nariño, traductor de la Declaración de los Derechos del Hombre y del ciudadano, puede ser reconocido como uno de los más importantes difusores de la concepción francesa de derechos políticos y sociales; para sentar uno de los precedentes jurídicos más importantes. Pero como se vio, sólo para el siglo XX hay una respuesta estatal unificada.

En lo sucesivo, los pueblos occidentales se dedicaron a luchar por la realización efectiva de estos derechos, lo que abrió paso al desarrollo de Constituciones de contenido democrático y social y posteriormente a la declaración de los Derechos Humanos, los Derechos del Niño, de la Mujer y demás, incluido el de la Seguridad Social. Paul Durand ha señalado que la formación histórica del Sistema de Seguridad Social ha pasado por tres etapas importantes:

"la primera es la que él llama Procesos Indiferenciados de Garantía, que son: el ahorro individual, la mutualidad, el seguro privado, la asistencia pública y la responsabilidad; la segunda es la de los seguros sociales y la tercera es la de la seguridad social"43.

La Revolución Industrial comienza en Inglaterra, con James Watt y la invención de la máquina de vapor (1784), lo cual mejoró los medios de transporte y comunicación en el creciente mundo moderno. A mediados del siglo XIX, con la aparición de las máquinas que sustituyeron la fuerza muscular y aumentaron la producción industrial, se generó un conjunto de cambios económicos, sociales, técnicos y culturales,

42 Al comienzo del presente trabajo se cita al libertador Simón Bolívar, en una frase recitada en el Congreso de Angosturas, seguido el pensamiento de Jeremías Bentham.

43 Rendón Vásquez, J. (1992). Derecho de la Seguridad Social. Lima: Tarpuy. 
que afectó directamente a la población que recién había hecho la transición de campesinos vasallos a obreros industriales. Las precarias condiciones de trabajo de la naciente organización industrial mecanizada, provoca fuertes tensiones sociales entre los empresarios que buscaban minimizar sus costos, y los trabajadores que buscaban maximizar sus salarios. Se pone de manifiesto el vacío en la gestión de la incertidumbre, que había sido abandonada en su gestión por estamentos privados como la Iglesia Católica, pero que ahora aparecían como un terreno baldío.

Como alternativa a estas condiciones de precariedad surge el ahorro privado, que permitía a los obreros eliminar los gastos innecesarios y cubrir aquellos de primera necesidad. No fue muy efectivo debido los bajos salarios que recibían los obreros; la mutualidad, que era un mecanismo de asociación sin ánimo de lucro, cuyo principio fundamental es la solidaridad y que permitió el desarrollo de lo que hoy se conoce como Seguridad Social; el seguro privado, apareció a finales del siglo XIX, como un contrato de derecho privado en el cual se pactaba el pago de una prima estimada de acuerdo al riesgo asumido por la aseguradora y ésta, a su vez, se obligaba a pagar el valor del seguro al producirse el evento incierto y futuro materia de la convención; la responsabilidad de los riesgos profesionales, la teoría del riesgo, defendida en Francia por Salleilles y Josserand (1897), constituyó un gran avance en el aseguramiento de los riesgos y contingencias laborales, pues los empresarios y/o empleadores que se acogían a ella, asumían los costos de las enfermedades o accidentes laborales aún cuando no tuvieran culpa de ello y por último la asistencia pública, que inicialmente se constituyó como la solución a los problemas de indigencia y desamparado de la época; pero con el desmesurado crecimiento demográfico, los altos índices de pobreza y la llegada de la revolución, tal propósito se había hecho de imposible realización y, sobre todo, para el Estado que carecía de medios económicos para cumplir con esta obligación.

Estos sistemas de ayuda, si bien eran una solución temporal a falta de un sistema de asistencia real, no ofrecían la seguridad que los asociados requerían, por lo que resultaban insuficientes económica y socialmente ${ }^{44}$. Un primer paso para la creación de un sistema que ofreciera verdadera protección a los obreros se inició en Alemania bajo la tutela del canciller Otto Von Bismarck, conocido como 'El Canciller de Hierro ${ }^{45}$, quien afirmaba que este sistema debía ser creado, dirigido y controlado por el Estado; a este sistema se llamó Seguro Social. El propósito era

44 El crecimiento demográfico vivido a comienzos del siglo XIX, originó una grave situación de orden político, económico y social a nivel mundial. En Alemania por ejemplo, de 25.000.000 de habitantes que tenía en 1800, pasó a 65.000.000 en 1890 .

45 Aunque Bismarck es llamado "El Padre de la Seguridad Social”, pues a él se le atribuye la creación de este sistema, Martínez Noval señala que en el año 1793, Condorcet un ilustrado matemático francés, motivado por sus inquietudes sociales, ya había ideado un sistema de reparto, un sistema que garantizaría pensiones para la clase de la que dice él "La clase más numerosa y productiva de la sociedad”, es decir, los trabajadores franceses. Martínez Noval, L. 2004. Los retos de la Seguridad Social. Madrid: MTAS, p. 204. 
desintegrar el naciente movimiento socialdemócrata obrero basándose en estructuras político-sociales como el Estado Bienestar ${ }^{46}$.Bismarck temeroso del "fantasma que recorría Europa”, tenía que contrarrestar su expansión con unas políticas sociales $\mathrm{y}$ económicas que beneficiaran al pueblo y debilitaran las fuerzas socialistas influenciadas por Marx y Engels; para ellos, los seguros sociales alemanes no nacen por motivos políticos, económicos o sociales sino por motivos ideológicos que son más poderosos que los otros tres juntos. ${ }^{47}$

Este proyecto fue presentado al parlamento con una gran aceptación entre los miembros y el 17 de Noviembre de 1881 el emperador Guillermo I hizo la presentación del nuevo sistema de seguros sociales de la siguiente manera:

"El interés de la clase trabajadora estriba no sólo en el presente, sino también en el futuro. A los obreros importa tener garantizada su existencia en las diferentes situaciones que puedan presentárseles, cuando sin su culpa, se ven impedidos de trabajar" ${ }^{\prime 4}$.

Básicamente el modelo de Bismarck se resume en una política social de bienestar que, a su vez, se divide en tres líneas: la ley sobre el seguro de enfermedad, el cual alcanzó consagración legislativa el 15 de Junio de 1883; la ley de seguro de accidentes de trabajo, disponiéndose que su financiación debía estar a cargo de los empleadores el 16 de Julio de 1884 y la ley de seguro de vejez o invalidez total, firmada el 22 de Junio de 1889;el 19 de Julio de 1911finalmente se promulgó el código de los Seguros Sociales, sin mucho significado de unificación de las nacientes leyes análogas al tema.

Los Seguros Sociales, establecidos en Alemania a fines del siglo XIX y comienzos del XX, fueron la fuente inspiradora de la seguridad social actual. Estos seguros sociales se crearon con el propósito de salvaguardar la relativa estabilidad que mantuviera a los trabajadores tranquilos para no desatar conflictos como los vividos en México en 1910 y en Rusia en 1917, a causa de la falta de políticas estatales proteccionistas que cobijaran a los obreros y sus familias. El seguro social ofrecía a los trabajadores asistencia social que corría a cargo del Estado. Estos seguros eran obligatorios, sin ánimo de lucro y cubrían los riesgos específicos de los trabajadores

46 "El Estado Bienestar consistió en un conjunto de reformas, políticas, sociales y económicas, implementadas a finales del siglo XIX y acentuadas a comienzos del siglo XX. A través de estas reformas el Estado asumió las tareas de proporcionar estabilidad general, crear un clima favorable al crecimiento económico, proteger mínimamente a la población económicamente débil o poco privilegiada a través de la extensión de la seguridad social y de los servicios sociales como salud, pensiones y educación. Sin embargo la tarea principal de producir los bienes y servicios necesarios fue dejada en manos de la empresa privada". Melo Moreno, V., y otros. (2005). Identidades 11. Colombia: Ed. Géminis., p. 87.

47 En referencia a que las fuerzas de poder de la época vieran al comunismo como una amenaza, reconociéndolo como una gran fuerza de tal manera que hicieron esfuerzos conjuntos para enfrentarlo. Marx, C., Engels, F. (1972). Manifiesto del Partido Comunista. Ed. Progreso, p. 29. 
subordinados.

Sin lugar a dudas, el desarrollo del proteccionismo estatal se dio gracias a Bismarck, hoy considerado como el padre de la "seguridad Social". Aunque no podemos dejar de lado otros sistemas y teorías que durante el mismo periodo abrieron otras ventanas para vislumbrar posibles vías de apoyo; caso el de la Ley de Speenhamland de 1795, la cual se caracterizó por los continuos ajustes en la atención a los trabajadores, a través del complemento de los salarios para garantizar la supresión de la mendicidad. La Ley de Pobres (Poor Law), de 1834 tenía como finalidad la supresión de los subsidios salariales y la limosna; esta ley extendió la atención social a los pobres capacitados para el trabajo, algo que no se ajustaba a la aparente lógica capitalista del momento ${ }^{49}$.

Son evidentes las diferencias entre los antiguos seguros sociales y la seguridad social como hoy la conocemos; cabría entonces hacer una comparación y establecer tales diferencias. Los seguros sociales cubrían los trabajadores, en tanto que el propósito de la seguridad social es el amparo de toda la población; los seguros sociales solo cubrían ciertos riesgos y contingencias sociales, la seguridad social está diseñada para cubrir todas las contingencias y riesgos sociales no sólo del trabajador sino de su familia. Como describe Fajardo

"Por razón de su organización y funcionamiento, la seguridad social es el sistema, la ideología, el movimiento, el mensaje, la filosofía; en tanto que el seguro social representa uno de sus órganos de expresión, uno de sus cuerpos gestionarios, o en su acepción restrictiva uno de sus establecimientos" $" 50$.

Con el nacimiento de la OIT (Organización Internacional del Trabajo) en 1919, durante el Tratado de Versalles y las conversaciones de paz luego de terminada la Primera Guerra Mundial, el mundo entero abrió sus puertas a las nuevas políticas estatales de proteccionismo o de Estado Bienestar; en todas las Constituciones se promulgó el derecho a la seguridad social al amparo del Estado. En la Constitución Política de la República de Weimar en 1919, en el artículo 119 se consagró constitucionalmente; en los Estados Unidos Mexicanos se ancla la seguridad social en la Constitución de Querétaro de febrero de 1917en el artículo 123, la cual se obtuvo producto del movimiento revolucionario liderado por Pancho Villa y Emiliano Zapata; en 1924 Bolivia adopta su ley de accidentes de trabajo y en Chile se promulga la primera ley de seguro social en Hispanoamérica, el 8 de septiembre de ese mismo año aprueba la ley 4.054, donde se implementa el seguro obrero obligatorio de enfermedad, maternidad, invalidez y vejez.

Desde 1900 hasta 1940 el auge de los seguros sociales tanto en Europa como en

49 Salazar Silva, F. (2005). La configuración del Estado de Bienestar. Elementos constitutivos. Vol. 7, N 014. Bucaramanga: Universidad Autónoma., p. 130.

50 Fajardo C, Martín. (1985). Derecho de la Seguridad Social. Lima, p. 33. 
América iba en considerable aumento. En España por ejemplo en 1900 se expidió la "Ley de Accidentes de Trabajo"; en 1908 se creó el Instituto Nacional de Previsión; en 1929 se estableció el "Seguro de Maternidad Obligatorio"; en 1938 se instituyó el régimen del subsidio familiar y en 1939 el subsidio de vejez, muchos años después redactó el Fuero del Trabajo, ley fundamental de alcance constitucional; un aparte del texto cita: "Por ser esencialmente personal y humano, el trabajo no puede reducirse a un concepto material de mercancía, ni ser objeto de transacciones incompatibles con la dignidad personal de quien lo preste”. Sin lugar a dudas en España se puntualiza la esencia de los principios de la seguridad social. Otro ejemplo, es el de Inglaterra; en dicho país nacieron movimientos obreros sindicales llamados Trade Unions, los cuales antes de la Primera Guerra Mundial, luchaban por conseguir el reconocimiento de los convenios colectivos de trabajo y la responsabilidad patronal en caso de accidentes de trabajo.

Al finalizar el siglo XIX, aparecen las Cámaras Sindicales y con ellas el seguro de desocupación por enfermedad y las cajas de retiros para la vejez. En 1911 se crean en Gran Bretaña los seguros de enfermedad e invalidez y el de paro forzoso; en 1925 el seguro de vejez, aunque ya se otorgaban beneficios a indigentes mayores de 60 años. En 1941 la Cámara de los Comunes nombró a Sir William Beveridge, para que presidiera una comisión que se encargaría de hacer el proyecto y estudiar el sistema de seguridad social, el cual se conoció como el "Plan Beveridge", trabajo que está contenido en la obra "Social Insurance Allied Services", el cual influyó notoriamente en la formulación de políticas claras sobre seguridad social en el mundo. Fue presentado en 1942, para reemplazar la asistencia pública por el Seguro Social y concertar la iniciativa individual al lado del seguro colectivo obligatorio. Para Beveridge el sentido de la seguridad social consiste en abolir el Estado de Necesidad, por una amplia redistribución de la renta. La extensión de la seguridad social a todos los integrantes de la población tiene por efecto establecer entre ellos una solidaridad que permita soportar más fácilmente la carga económica.

En Francia por su parte, el seguro social se hace obligatorio en 1898, aunque su desarrollo fue más lento que en Alemania e Inglaterra; en 1910 se adoptó la ley de pensión de vejez, el cual fue ineficaz por su bajo monto; el 4 de Octubre de 1945 mediante ordenanza, se promulgo el Sistema de Seguridad Social Francés que rige en la actualidad, el cual tiene por finalidad cubrir a los trabajadores franceses y sus familias todos los riesgos sociales; la Constitución de 1946, garantiza a todos los franceses la seguridad social, el descanso y el tiempo libre.

En los países socialistas se introdujo la seguridad social como un derecho gratuito para toda la población; en la Constitución Soviética de 1918, tras la Revolución Bolchevique y la retirada de Rusia de la Primera Guerra Mundial, se promovió la gratuidad en el cubrimiento de los riesgos sociales; de igual forma sucedió con las Constituciones de la extinta URSS de 1924, 1936 y 1977. Estos sistemas también aplicaron a los demás países socialistas dispersos en el mundo; muestra de ello la encontramos en Cuba, donde aún se conservan vivos los ideales socialistas, pese 
a la caída de este sistema en Europa. En la república de Cuba, lo concerniente a la asistencia médica y hospitalaria es gratuito, para todos los ciudadanos. Estas disposiciones tienen plena vigencia en la actualidad; de allí que Cuba ocupe el primer lugar en la cobertura de seguridad social en América Latina.

Hasta aquí podemos concluir que los seguros sociales se originaron en Alemania a finales del siglo XIX, con una creciente expansión por todo el mundo, dadas las necesidades urgentes de satisfacer una demanda social que se encontraba desprotegida. Hasta aquí la seguridad social se dividió en dos etapas, la primera data de 1760 a 1834 en la cual predominó el sistema de subsidios, práctica de la asistencia acompañada de un cierto paternalismo social; la segunda etapa viene de 1834 a 1883 en la cual bajo la necesidad de la supresión de subsidios, y con el objeto de forzar la entrada de las personas al mercado laboral, se diseña una política de contribución de recursos bajo el esquema de prestaciones laborales que brinda con ellas a los obreros la posibilidad de recibir asistencia para sí mismos y sus familias.

Existen dos etapas más en la evolución histórica de la seguridad social: una que cobija desde 1883 hasta 1988 y desde 1988 hasta nuestros días. Cada una de estas etapas cobija momentos históricos en la evolución de la humanidad que no se pueden obviar y que estudiaremos a continuación:

La expresión "Seguridad Social”, en el sentido que la entendemos actualmente, apareció en el mundo occidental en Estados Unidos de América donde se utilizó por primera vez el término Seguridad Social, en sentido moderno. Como consecuencia de la gran depresión económica de 1929, el presidente Roosevelt, emprendió una abierta política intervencionista en materia económica y social, con coberturas entre otras al desempleo. La Social Security Act del 14 de Agosto de 1936 fue promulgada durante el primer gobierno del presidente Franklin Delano Roosevelt (New Deal).

Guillermo Cabanellas de Torres (2001), menciona que entre sus propósitos tenemos: sistemas de asistencia y de retiros o pensiones a la vejez con subsidios, ayudas a familias numerosas, protección a madres viudas que trabajen con hijos menores de edad y protección a los ciegos, entre otros. La Social Security Act, tenía como finalidad hacer frente a la crisis económica que asolaba el país, erradicar la miseria y evitar los conflictos sociales que se pudiesen generar como consecuencia de esta crisis. Pero fue en Nueva Zelanda, el 14 de Septiembre de 1938, donde se promulgó la "Ley de Seguridad Social", que tuvo influencia decisiva en la legislación mundial en la materia, por lo novedoso de sus principios que superaba el tradicional enfoque de asistencia pública. La Organización Internacional del Trabajo, realizó la difusión de tan importante normativa, ya que en ella se expuso mejor que en cualquier otra legislación el significado y fin práctico de la seguridad social.

El 14 de Agosto de 1941, en plena Segunda Guerra Mundial, el entonces presidente de los Estados Unidos Franklin Delano Roosevelt y el primer ministro Británico Sir Winston Churchill, se reunieron para coordinar los esfuerzos de la guerra contra la Alemania nazi y el Japón militarista; en dicha reunión se produce la "Carta Del Atlántico", suscrita por ambos países, en la cual en el punto 5 del texto señala "Todas 
las naciones tienen el deber de colaborar en el campo económico - social, a fin de garantizar a sus ciudadanos las mejores condiciones de trabajo, de progreso económico y de seguridad social'”. Dicha proclama también quedó consignada en la "Declaración de Washington” de 1942.

Acto seguido se celebró en Santiago de Chile en Septiembre de ese mismo año, la I Conferencia Interamericana de Seguridad Social, en la cual se formula la Declaración de Santiago y en la que se proclama:
"Cada país debe crear, mantener y acrecentar el valor intelectual, moral y físico de sus generaciones venideras y sostener a las generaciones eliminadas de la vida productiva. Este es el sentido de la Seguridad Social: Una economía auténtica y racional de los recursos y valores humanos (...), que las decisiones de América en orden a la nueva estructura de la Seguridad Social, constituyen un aporte a la solidaridad del mundo en la conquista del bienestar de los pueblos y al logro del mantenimiento de la paz."

De esta manera, como algo ajeno al desenvolvimiento institucional endógeno de los países de Latinoamérica, se importa el furor europeo por las tendencias proteccionistas hacia los trabajadores y sus familias, que luego pasaría a cobijar a todos los miembros de la colectividad. Se produce entonces entre los años 1943 y 1945 una actividad legislativa sin precedentes en torno a la materia. En Costa Rica por ejemplo, en 1943 se elabora el Código del Trabajo y de reforma del Seguro Social; Ecuador actualiza su Ley de Seguro Social; México publica un reglamento de Seguro Social; Panamá promulga una Ley de Seguro Social Integral; Paraguay impone el Seguro Social Obligatorio e Integral que cubre todos los riesgos; Uruguay crea las Cajas de Compensación; Haití implementa la indemnización de accidentes de trabajo y crea los establecimientos sanitarios para la vejez.

Estas cartas y declaraciones dieron lugar a la Declaración de Filadelfia proferida en 1944 por la 26a reunión de la conferencia de la OIT celebrada en dicha ciudad. En dicha conferencia se ratificó que

"La paz permanente solo puede basarse en la justicia social", y entre los objetivos, el punto sexto del texto cita "Extender las medidas de seguridad social para garantizar ingresos básicos a quienes los necesiten y prestar asistencia médica completa".

En Brasil la Ley Orgánica de los Seguros Sociales, recoge mejor que nadie las recomendaciones de Filadelfia en esta materia.

Además de estas, un antecedente se encuentra en una declaración que fue aprobada por la Asamblea General de la ONU celebrada en París el 10 de Diciembre de 1948; dicha es "La Declaración Universal de los Derechos Humanos". Lo relativo a la seguridad se encuentra consagrado en los artículos 22, 23 y 25; el Artículo 22:

"Toda persona, como miembro de la sociedad, tiene derecho a la seguridad 
social, y a obtener, mediante el esfuerzo nacional y la cooperación internacional, habida cuenta de la organización y los recursos de cada Estado, la satisfacción de los derechos económicos, sociales y culturales, indispensables a su dignidad y al libre desarrollo de su personalidad".

El Artículo 23 versa: "Toda persona que trabaja tiene derecho a una remuneración equitativa y satisfactoria, que le asegure, así como a su familia, una existencia conforme a la dignidad humana y que será completada, en caso necesario, por cualesquiera otros medios de protección social”.

$Y$ el Artículo 25 establece: "Toda persona tiene derecho a un nivel de vida adecuado que le asegure, así como a su familia, la salud y el bienestar, y en especial la alimentación, el vestido, la vivienda, la asistencia médica y los servicios sociales necesarios; tiene asimismo derecho a los seguros en caso de desempleo, enfermedad, invalidez, viudez, vejez u otros casos de pérdida de sus medios de subsistencia por circunstancias independientes de su voluntad". ${ }^{1}$

Estos principios fueron divulgados en todo el mundo occidental, así mismo fueron incorporados en la Carta de Libertad Europea el 4 de Noviembre de 1950. Luego del surgimiento de la Norma Mínima de Seguridad Social (102), convenio expedido por la XXXV Conferencia General de la OIT el 28 de Junio de 1952 y que actualmente no ha sido ratificado por Colombia, que recoge los objetivos de acción protectora, estos principios se incorporaron a la mayoría de las legislaciones del mundo tanto de países altamente desarrollados, como los que se encuentran en proceso de desarrollo.

Los mismos principios aparecerían poco después en la Carta Social Europea del 18 de Octubre de 1961; en el Pacto Internacional de Derechos Económicos, Sociales y Culturales de las Naciones Unidas del 16 de Noviembre de 1966; en la Convención Americana de Derechos Humanos del 22 de Noviembre de 1969; y en las Declaraciones Iberoamericanas de Seguridad Social de Buenos Aires 1972 y Panamá 1976; en las cuales quedó ratificado indefectiblemente que el hombre por el solo hecho de su condición, tiene derecho a la seguridad social, y por tal se entiende la cobertura integral de los riesgos y contingencias y la garantía de los medios para el desarrollo pleno de su personalidad. Tal como lo comenta Ahumada:

"La cobertura de los riesgos sociales a través de la historia como se ha dejado entrever, ha experimentado una constante y vasta evolución. Comenzando por la cobertura de los riesgos relacionados con la vida del hombre, para pasar luego a cubrir los riesgos derivados de su trabajo, y mucho más tarde, hasta alcanzar la fisonomía moderna que implica la idea de cobertura de todos los Estados de necesidad". ${ }^{2}$ 
Sin duda alguna, el desarrollo histórico de la seguridad social en el mundo ha atravesado por innumerables etapas desde su primera concepción como un sistema asistencial hasta lo que representa en nuestros días todo esto se ha evidenciado no sólo en normas legales nacionales sino en fuentes de derecho internacional.

Con esto se finaliza el recorrido espacio temporal propuesto para esta sección, se espera que la senda histórica y espacial trazada en este texto pueda ilustrar con propiedad acerca del surgimiento de los sistemas de seguridad social tanto en Colombia, como en los países del hemisferio occidental. Se aspira a que se haya podido demostrar que aunque la provisión del ser humano ante los hechos que guardan altas dosis de incertidumbre y que involucran su subsistencia material han sido concebidos durante el último siglo como una función propia del Estado, esto no ha sido siempre así, sino que en numerosos episodios de la historia humana pueden encontrarse sistemas complejos de provisión frente a las catástrofes naturales, las hambrunas, la vejez y la enfermedad.

Además que aquella relación indisoluble entre Seguridad Social y Estado, es un concepto muy reciente y que ha derivado en una capacidad de coacción económica muy pronunciada por parte del Estado, a través de sus cargas impositivas. Ahora con la crisis mundial cabe al menos cuestionarse si luego de un siglo de crisis económicas causadas en gran parte por la intervención del Estado, no va siendo hora de dejar que los sistemas complejos de las sociedades libres puedan dar los frutos de su acción espontánea. La crisis fiscal que lleva Europa sobre si tiene el rasgo inconfundible de la indisciplina fiscal y del proteccionismo frente al comercio internacional.

Como idea final quisiera expresarse que no debe confundirse, de manera deliberada y repetitiva los servicios de bienestar general con la provisión pública de los servicios. Puede existir una sociedad del bienestar, sin necesidad de un Estado de Bienestar, el ejercicio pleno de la libertad exige de los ciudadanos la mayor observación a sus principios y su responsabilidad, en este sentido, los empresarios y los trabajadores no debe seguir cargando con la carga impositiva que impone el estado sobre sus hombros, so pretexto de que los protege. Tal vez sea del Estado de lo que haría falta que se protegiesen, el resto sólo dependerá de su capacidad productiva. Tal vez sea hora que los individuos sean tratados como mayores de edad y puedan agenciar las consecuencias de sus actos, aunque en la mayoría de los casos, sus efectos llegarán a ser completamente diferentes.

Una sociedad del Bienestar puede alcanzarse en la medida que las personas puedan aprovechar su conocimiento y el de los demás de forma recíproca, desarrollar al máximo sus capacidades y destrezas y fomentar su creatividad, tal como lo propone, el premio nobel de economía Friedrich August von Hayek:

"en la sociedad libre es esencial que el valor del hombre y su remuneración no dependan de la capacidad en abstracto, sino del éxito obtenido al traducirse en servicios útiles a los otros y que a su vez estos otros puedan permutar. El principal objetivo de la libertad es ofrecer oportunidades e incitar al individuo para que se asegure el máximo uso de conocimientos que pueda adquirir. Lo 
que hace al individuo único a este respecto no es su conocimiento genérico, sino su conocimiento concreto: su conocimiento de las circunstancias y condiciones especiales." ${ }^{, 53}$

Las crisis económicas, aún con su dureza, tienen la virtud de mostrar que algo no funciona bien dentro del esquema productivo, la crisis que se vive en occidente a día de hoy, ha mostrado la inviabilidad de un Estado con un peso fiscal demasiado grande y poco efectivo en el cumplimiento de sus obligaciones sociales. Aquella promesa de reconocimiento político a cambio de bienestar, ha quedado en duda, toda vez que no es posible desangrar más la empresarialidad y la capacidad de trabajo de los ciudadanos, tal vez sea hora de ver en el funcionamiento del mercado una opción real para el ejercicio de la libertad de los ciudadanos y no simplemente ofrecer una dádiva que los conduce al desastre.

\section{REFERENCIAS}

Ahumada Pacheco, H., (1972). Manual de Seguridad Social. Ed. Andrés Bello. Chile.

Bernedo Alvarado, J. (2000), Informe regional sobre la situación de la Seguridad Social como un Derecho Humano en América Latina. Lima, Perú.

Buen Lozano, N., Morgado Valenzuela, E., (1997). Instituciones de derecho del trabajo y de la seguridad social. Universidad Nacional Autónoma. México.

Cabanellas de Torres, G., (2001). Diccionario de Derecho Laboral. Ed. 1. Heliasta. Buenos Aires.

Cadavid Gómez, I. y Arenas Gallego, E. (2007). Cartilla del Trabajo. Medellín: Universidad de Medellín.

Constitución Política de Colombia (1991). Artículos 44, 46, 48 y 49.

Declaración Universal de los Derechos Humanos. (1948). Artículos 22, 23 y 25.

De la Cueva, M. (1959). Derecho Mexicano del Trabajo. Tomo I, p. 41. México: Porrúa.

Ely Yamín, A. (2006). Los derechos económicos, sociales y culturales en América Latina: Del invento a la herramienta. México: Plaza y Valdés Editores, p. 255. Envío No. 24. (2006). Régimen de Seguridad Social en Colombia. Legis.

Fajardo C, Martín. (1985). Derecho de la Seguridad Social. Lima, p. 33.

Flórez, K (2011). La competencia Regulada en el sistema de salud colombiano. Revista Lebret, 2, 48-73.

Gil, V. J., Canales Aliende, J. M. y Orjuela Ramírez, M. E. (2009). Estado del bienestar y políticas sociales: Una aproximación a la situación española y colombiana. Alicante (España). Editorial Club universitario, p. $214-215$.

53 Hayek, F. A. Los fundamentos de la libertad. Ediciones Folio. Tomo I. p., 104. 
González Roaro, Benjamín. (2003). La Seguridad Social en el mundo. México, Buenos Aires: Siglo XXI Editores.

Greco R. (1968), Revista de Seguridad Social, N 6, 518. Buenos Aires.

Grisolia, J. (2003), Derecho del Trabajo y de la Seguridad Social, (p. 923). Buenos Aires: Ediciones Desalma Lexis Nexos.

Hayek, F. A. Los fundamentos de la libertad. Ediciones Folio. Tomo I. pág., 104.

Kant, I. (2004) ¿Qué es la Ilustración? Alianza Editorial. Madrid

Mallet, A., (1983). Estudio de la Seguridad Social: La Búsqueda de la Seguridad Social. Ginebra, p. 78.

Martínez Noval, L. 2004. Los retos de la Seguridad Social. Madrid: MTAS, p. 204.

Marx, C., Engels, F. (1972). Manifiesto del Partido Comunista. Ed. Progreso, p. 29.

Melo Moreno, V., y otros. (2005). Identidades 11. Colombia: Ed. Géminis., p. 87.

Ministerio de la protección Social e Instituto de Seguros Sociales. (1993). Ley de Seguridad Social (Ley 100). Preámbulo, Cap. I, Artículos 1, 2 y 3.

Oficina Internacional del Trabajo. (2001). Conclusiones relativas a la Seguridad social. Seguridad Social: Un nuevo consenso, pp. $1-2$.

Olea, A., (1959). Instituciones de seguridad Social. Instituto de Estudios Políticos. $1^{\text {a }}$. Edición. Madrid.

Pérez Leñero, J. (1956), Fundamentos de la Seguridad Social. Aguilar Editores. Madrid.

Perona, N, (2000). Vulnerabilidad y Exclusión social. Una propuesta metodológica para el estudio de las condiciones de la vida de los hogares. Revista Kairos. Universidad Nacional de San Luis. Argentina.

Plazas, G. (1994). La nueva Seguridad Social: Un texto comentado de la Ley 100 de 1993. Bogotá: Linotipia Bolívar S. en C.

Rendón Vásquez, J. (1992). Derecho de la Seguridad Social. Lima: Tarpuy.

Rodríguez Meza, R. (2009). Estudios sobre Seguridad Social. Barranquilla: Ediciones Uninorte.

Salazar Silva, F. (2005). La configuración del Estado de Bienestar. Elementos constitutivos. Vol. 7, N 014. Bucaramanga: Universidad Autónoma., p. 130.

Tónnies, F (2009). Comunidad y Asociación. Editorial Comares. Granada

Valcárcel, L. E. (1964). Historia del Perú antiguo Incas. T. 1. Lima. Ed. Juan Mejía Baca, p.35.

Weber, M. (1993) Economía y Sociedad. Alianza Editorial. Madrid 
